\title{
Establishment of an Electronic Curriculum Group to Enhance the Effectiveness of Electrical Teaching Reform
}

\author{
Liu Yanfei ${ }^{1, a}$, Tian $\mathrm{Qi}^{1, \mathrm{~b}}$, Wang Le $\mathrm{e}^{1, \mathrm{a}}$ and Luo Dacheng ${ }^{1, \mathrm{~b}}$ \\ ${ }^{1}$ Xi'an Research Institute of High Technology, Xi'an 710025, China. \\ abbmcu@126.com, bqdtianqi@163.com
}

Keywords: Electrical Courses; Teaching System; Teaching Reform; Engineering Practice Ability

\begin{abstract}
This paper discusses the teaching reform of electrical courses based on the experimental classes in the school. Reform has broken the limit of theory, practice and experiments and established the system of electrical courses. Especially, on the basis of "iboard pocket experiment box", it had the remarkable effect. Practice shows that the teaching reform stimulates the interest of students in learning electronic technology, and enhances the ability of autonomous learning, practice and innovation.
\end{abstract}

\section{Introduction}

"Circuit Analysis Basis", "Analog Electronic Technology", "Digital Electronic Technology" and related experiments, practice courses are the compulsory engineering technology curriculum of this major in our school. These courses are also first contacted with engineering and technical courses for undergraduate students.

This series of courses take basic circuit analysis, analog and digital logic circuit design as the main content, aiming at helping students be familiar with basic electrical theory, grasp the basic circuit design methods, understand the forefront development of modern electronic technology, and develop the electrical and electronic capabilities. The engineering work of our school needs various types of circuit theories, designs, and practical experience without exception[1]. The knowledge points of those three courses ("Circuit Analysis Basis", "Analog Electronic Technology", "Digital Electronic Technology") and the analysis and design methods have become indispensable in each subsequent course. Electrical courses play an important role as a bridge between basic courses and professional courses which are also important foundation for the smooth implementation of subsequent courses[2].

With traditional teaching methods, teachers tended to pay much attention to theory and equation, and less attention on developing engineering capacity. So the engineering capacity of students cannot be improved effectively. With the rapid development of information technology and electronic science meanwhile that technology is widely used in modern society, the traditional teaching content and methods can not satisfy the demand for a full range of electrical courses, so the reform efforts have large potential.

\section{Reform of Objectives and Content}

In recent years, we explores the reform methods of Electricity Course with the implementation of knowledge combing, docking and specialized courses, after-school design or big job, illustration style teaching method combined with domestic and international experience of teaching reform, the actual situation of our school, to locate and build basic electronics courses conducting serious thinking, and develop guidelines and methods for curriculum reform[3].

\subsection{Reform goals}

Through deepening reform of basic electronics courses, retain programs and other related courses, dilute the integrity and independence of each course each system, break the course category intervals, in accordance with the needs of engineering practice, the circuit-mode teaching content number of electric various courses becomes closer to the engineering ability objectives and requirements of training program in basic, connection transition becomes more smoothly between the three courses, complement each other with experimental courses, with connection transition 
Prerequisites and follow-up courses more reasonable increasing in theory Teaching exercises or curriculum design, and strengthen the knowledge of comprehension, and application. Form a "circuit, analog circuit, digital circuit" three core theory courses, including circuits and electronic technology experiment, electronic system design, microcontroller basic theory, experiment, practice courses, and courses in basic electronics cluster ring phase which become a overall deduction, organic integration. Finally, a large group in basic electronics courses with a clear goal, rational content, which are well-organized and smooth.

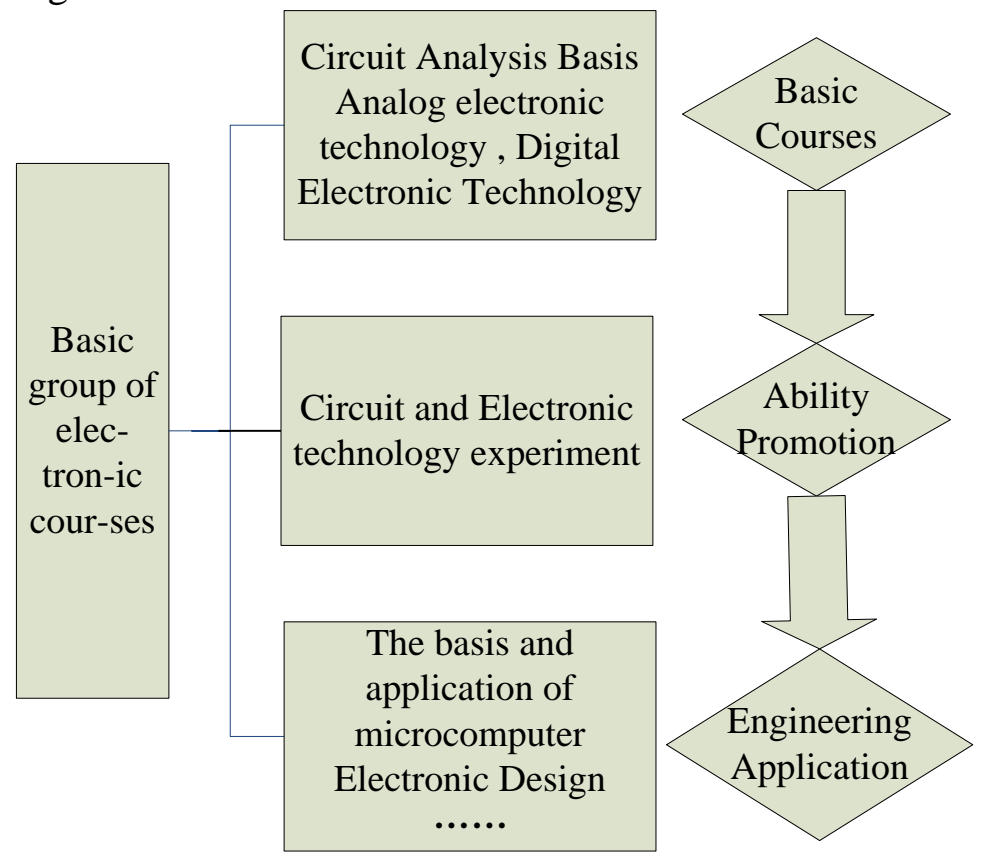

Fig. 1 Great basic electronics courses Group

\subsection{Reform of contents}

The three-point organic knowledge restructuring was completed in organizing reform class teaching content aimed at the target of Engineering Technology Training Course for students, and the electronic technology courses Project characteristics was reflected[4].

1. The establishment of "Circuit Analysis" project ideas

The teaching objectives were always focused more on training students with the general engineering concepts and ideas, by teaching general theory and analysis method based on the integration of the circuit element engineering knowledge, quiz simulation, practice quizzes, other engineering applications and related links, culture. students have perceptual knowledge engineering applications in the organization and content enhancement mode power adapter curriculum content knowledge to pave the way follow-up courses will focus on the circuit controlled source model curriculum applied steering describes the nature of the test from the computing power, increase content filter circuit principle echoes sinusoidal oscillation circuit frequency selection circuit.

2. "Analog Electronic technology" to achieve functional circuit design

Strengthen the interface with the electrical circuit and several courses in the teaching content, teaching objectives in a more general focus on developing methods and skills for students to grasp the whole concept of electronic systems and electronic systems analysis and design. Our current electronic system based mainly practical integrated circuit, organize lectures reorganize the order, the "first integrated, after the separation," the order, and appropriate changes in parts. This benefit is "consistent with the practical application, and can effectively link up with the circuit course." The reason is that, if we neglect the internal structure of integrated operational amplifiers, integrated transportation on the course can be equivalent to a "controlled source", constituted by the op amp voltage amplifier, current amplifier, voltage-current conversion circuit and the current-voltage conversion circuit happens to be four specific forms of controlled source to the above start-mode teaching curriculum, so that students readily accepted and will not start directly into specific device from a purely theoretical course, avoid jumping thinking, science Shun the convergence relationship. In the process of teaching in the classroom simulation and experimental validation based on the 
increase of the "Practical Electronics System Design," Great job links courses under, so that students appreciate the analysis and practical electronic systems design, installation, commissioning, the whole process of testing, hands-on practice and innovation ability is improved.

3. "Digital Electronic Technology" to complete the circuit design engineering

On teaching objectives to focus more on training students for analysis and design methods of modern digital electronic systems of control, the use of FPGA technology to deepen the basic knowledge and understanding of the depth of the circuit, I will explain the school to promote the knowledge of digital electronic technology into the 21st century. For this to be taken "in the small-scale integrated device hardware implementation and realization of FPGA-based software," two lines parallel advance teaching ideas, in explaining the traditional bottom-up design patterns at the same time, the introduction of top-down, modern design the method in the study of digital circuits while simultaneously supporting learning FPGA, so that students master the basis of a general digital system hardware implementation, the initial grasp of the EDA modern digital system implementation[5].

4. Pocket through three experimental electric box --iboard basic course

In the use of "Circuit Analysis Basis" Course iboard achieve discrete identification, basic functional circuit test, the use of experimental boxes iboard completed on all kinds of demonstration experiment class, on the one hand deepen the participants' perceptions and understanding of the theoretical knowledge, on the other hand, so that students are familiar with the use of the instrument interface operation iboard in the process, enhance the participants' desire to learn the electronic system, to facilitate follow-up courses to start the task. "Analog Electronic Technology" course combining lectures on iboard functional circuits are analyzed, interspersed with some of the features iboard circuit design, "Digital Electronic Technology" After the completion of the entire course combines FPGA iboard engineering design.

5. Course Assessment reflect engineering ideas, guide curriculum reform

By Proposition Course Assessment Examination, coursework and test scores usually constituted 60 per cent respectively of the total score, $20 \%$ and 20\%. Theoretical Examination after the end of the course of study, in addition to the classical theory and methods, the engineering examples set testing theory and methods subject to examination content guide curriculum reform, reform of test results[6].

\section{Reform of Features and Innovations}

Breaking theory, experiment, practice boundaries, unified planning "Electric \& Electronic Course group" content system, teaching content organization in accordance with the actual situation of the students and teaching requirements, updates traditional curriculum with new devices, application specific integrated circuits.

In the process of teaching theory courses, we introduced EDA simulation technology, the establishment of a "EDA simulation design and physical demonstration" a combination of curriculum design model to achieve theoretical classroom transformed into a "Project Design Laboratory" to achieve in theory and practice classroom unity[7].

In the implementation of experimental course of taking the traditional test and EDA simulation method combining using Project of traction experimental teaching methods, to create a new model of teaching in engineering practice characteristics, thus greatly improving the students' interest and Teaching Quality[8].

\section{Conclusion}

In the experimental teaching reform in our college, it has been achieved some success, to stimulate the interest of students studying electrical courses, improve student ability, innovation and engineering capabilities, which, in particular, is based on "iboard pocket experiment box "traction Engineering teaching is well received. At the same time in the implementation process also found some difficulties, such as when to carry out the simulation and physical experiments to maximize 
the show to enhance teaching effectiveness in the classroom, the choice of assessment methods can verify the results of education reform is still need further study.

\section{References}

[1].Chang Qingmei, Sun Liang. Power Core Curriculum Teaching Reform and Practice [J], China Electric Power Education, 2012(18), 60-61

[2].Yao Yingying, Fan Chengzhi, Lin Ping. Electric Research and Practice class technology curriculum reform [J], China University Teaching, 2012(3), 54-56

[3].Hu Zhizhong, Wang Chenghua. "Modern Electronics Technique" Course Reform and Practice [J], Journal of EEE, 2015(1), 32-34

[4]. Wang Zhigong, Xu Jian, Ma Li, Zhao Xintai, Wang Weiwei. Experimental Boards for the Teaching of Electric and Electronic Circuit Course [J], Journal of EEE, 2014(6), 96-99

[5].Gong Zhaowen,Zheng Junli. Historical circuit course, current situation and prospects [J], Journal of EEE, 2011(6), 5-12

[6].Yu Xinjie,Zhu Guiping, Lu Wenjuan, Liu Xiucheng, Guo Jingbo, Zhao Wei. The Educational Reform of Electric Circuits Cours [J], Journal of EEE, 2012(1), 1-8

[7] Dong Jiajia, Yu Qinjie. Construction of electrical engineering discipline characteristics of Practice Teaching System [J], Laboratory Research and Exploration, 2012(4), 132-135

[8] Li Jingya. Teaching Reform for Circuit and Analog Electronic Technology [J], Journal of EEE, 2015(4), 62-64 